\title{
EL IMPACTO DE LA PANDEMIA DEL COVID-19 EN LOS CONTRATOS DE OBRA EN LA REALIDAD PERUANA
}

\author{
THE IMPACT OF THE COVID-19 PANDEMIC ON \\ WORK CONTRACTS IN THE PERUVIAN REALITY
}

Cesar Torres-Calderón Z. * Docente universitario, conciliador extrajudicial y especialista en
Derecho a la Construcción

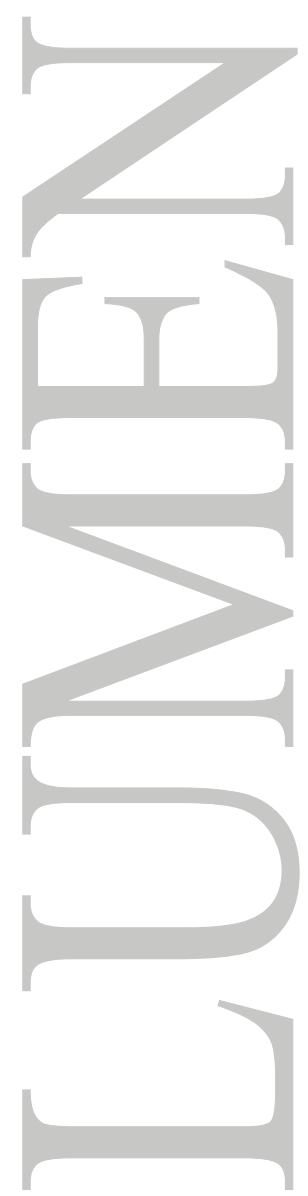




\title{
EL IMPACTO DE LA PANDEMIA DEL COVID-19 EN LOS CONTRATOS DE OBRA EN LA REALIDAD PERUANA
}

\author{
THE IMPACT OF THE COVID-19 PANDEMIC ON WORK \\ CONTRACTS IN THE PERUVIAN REALITY
}

Cesar Torres-Calderón Z.

\begin{abstract}
RESUMEN
Un novísimo panorama se presenta en el mundo, por la presencia de la propagación del COVID- 19 que ha generado una nueva forma de convivencia, el derecho no ha sido la excepción a las transformaciones surgiendo conflictos jurídicos, específicamente en el derecho de contratos, en lo referido al contrato de obra donde ha repercutido los nuevos comportamientos de los sujetos que intervienen, de los peculiares incumplimientos por causa de un evento de fuerza mayor que interrumpe un normal desenvolvimiento de un contrato de construcción, que incide en la rescisión de contratos, cual es el impacto de la fuerza vinculante y las restricciones o limites gubernamentales respecto a los trabajadores, así como la repercusión de las medidas del estado en los contratos de construcción. De allí que el objeto de nuestra estudio sea determinar como el impacto de la pandemia del Covid-19 en los contratos de obra en la realidad peruana. Es un trabajo de enfoque cualitativo, puesto que utilizara los métodos de observación y análisis de textos.
\end{abstract}

\section{PALABRAS CLAVE}

Contrato de obra, pandemia, incumplimiento.

\begin{abstract}
A brand new panorama is presented in the world, due to the presence of the spread of COVID- 19 that has generated a new form of coexistence, the law has not been the exception to the transformations arising legal conflicts, specifically in the law of contracts, in regarding the work contract where the new behaviors of the subjects involved have affected, the peculiar breaches due to an event of force majeure that interrupts a normal development of a construction contract, which affects the termination of contracts, which it is the impact of the binding force and government restrictions or limits on workers, as well as the impact of state measures on construction contracts. Hence, the purpose of our study is to determine how the impact of the Covid-19 pandemic on construction contracts in Peruvian reality. It is a qualitative approach work, since it will use the methods of observation and analysis of texts.
\end{abstract}

\section{KEY WORDS}

Construction contract, pandemic, non-compliance.

\section{INTRODUCCIÓN}

De repente el mundo despertó con una noticia estremecedora, la presencia de un virus letal, que se iba propagando velozmente desde su lugar de incubación en China denominado Covid-19 o "coronavirus", que llego a Europa primero a Italia, por la activa relación de comercio y turismo que se tenía con el país oriental, y de allí se extendió a todos los países del viejo continente y a través de los medios de transporte especialmente el aéreo llego a los otros continentes y por ende al Perú y a los otros países de la región, se comenzaron a contar las muertes por decenas, centenas y miles, y los diversos países presentaron diversas estrategias para combatirla, por ser un virus con nuevas características a otras, pero con una letalidad que cobraba vidas humanas. Ante dicha situación el estado desarrollo políticas públicas de prevención y medidas las principales ciudades y después 
en todos el país, como en nuestro caso, está medida de emergencia para que sea efectiva tiene que durar un determinado periodo en algunos casos como en China duro 6 meses y aun con el término del asilamiento en la experiencia comparada observamos que hay presencia de rebrotes, podríamos hablar de mayor exigencia de tiempo de aislamiento, esta política de los estados para combatir el virus cambio la vida de las personas, pero sobre todo en las relaciones jurídicas, como en el derecho de contratos y en especial los contratos de obra.

Hemos visto la complejidad de las políticas públicas dictadas por este gobierno para disminuir las consecuencias fatales que estamos viviendo los peruanos con esta pandemia, se siguen evaluando si las decisiones fueron acertadas, como estado o autoridad tiene el poder de decisión, los recursos tanto económicos, material y humanos para hacerlo. Es una tarea con una responsabilidad que no solo va tiene efectos en determinadas personas sino en todo el país y en las instituciones jurídicas.

La "situación extraordinaria" del Covid-19 origino una serie de problemas y contratiempos en la vida de los peruanos y sobre todo en las relaciones jurídicas, como en el caso de los contratos, la respuesta jurídica si bien es cierto esta previstos en nuestro derecho sustantivo como el caso de "caso fortuito", "fuerza mayor", la realidad exige una nueva lectura para poder darle solución al tratamiento jurídico en torno a los incumplimientos, ya no por una acción intencional, sino por un supuesto impedimento que es parte de la política gubernamental para luchar contra este mal, surgiendo diversas controversias en los contratos de obra, por ello en base a una lectura personal del problema, revisión de la experiencia comparada y material bibliográfico especializado, vamos a comprender la magnitud del problema, analizarlo y dar algunas alternativas de solución.

\section{Los efectos en la sociedad por la pandemia del Covid-19}

La crisis sanitaria originada por el Covid-19, es un hecho extraordinario que no se puede comparar con otros hechos similares en la historia, donde como hemos visto la propagación del virus presenta nuevas modalidades de contagio, por ello se planteó políticas de urgencia para detener su avance, nuestro país como todos los países, emitió una serie de normas con acciones urgentes en la esfera económica, política y social.

El presidente peruano Martín Vizcarra y su consejo de estado conformando un grupo de expertos sobre el tema, inicio su trabajo para detener el contagio, declaro todo el país en estado de emergencia y paulatinamente se fueron incrementando las restricciones de derechos fundamentales, cuarentena, aislamiento social, toque de queda y por lo tanto una inmovilización de las personas, a excepción de las personas que se dedican a la salud y a los que se dedican al intercambio de bienes de primera necesidad.

La finalidad de las políticas públicas es utilizar los instrumentos que tiene el estado para transformar una realidad o para modelar una realidad imperfecta, como esta situación genuina del mundo y de nuestro país como es la pandemia, fue difícil y complejo tomar decisiones, sobre todo en un país democrático, donde hay diferentes, variadas y complejas posiciones. Muchas veces las decisiones tienen estrecha relación con los actores de la política y como sabemos cada uno de ellos tiene su propia lectura de la problemática. Se buscan diferentes argumentos desde explicaciones específicas y otras más argumentativas sobre todo cuando existe un periodo presidencial o cuando hay enconados rivales políticos.

Se ha criticado las medidas impuestas y se siguen criticando tenemos el ejemplo de Estados Unidos que optó en los primeros meses de la pandemia por la economía, y está pagando con 
miles de fallecidos dicha política, desde nuestra óptica la decisión publica del presidente fue la más acertada optar por el aislamiento desde el primer momento, obviamente ello significó la paralización de las fuerzas productivas, hay que destacar que se pensó que las medidas eran temporales que no excederían de 15 días o un mes, no que se prolongaría meses y que aun estando al principio del mes de junio no se sabe a ciencia cierta cuanto va durar el periodo de aislamiento El estado también emitió diversas medidas con carácter de urgencia como el caso de los subsidios, los denominados "bonos" individuales, universal, rural, facilidades para obtener el retiro de un porcentaje de los aportes de la AFP, inyección de capital a ciertos sectores de la economía entre otros. Todo ello tuvo un impacto en todas las esferas de la sociedad, el mayor fue en la economía, al quebrarse la dinámica de la circulación de la riqueza aparecieron nuevos problemas. La situación lamentablemente se está desbordando las personas tienen más miedo a pasar hambre que contagiarse del virus y salen a las calles y los contagios se multiplican y hasta hoy no logramos descender o llegar al tope de los contagios, quiere decir que los problemas van a continuar y las medidas que tome el gobierno pueden ampliarse.

Sobre los efectos de la pandemia que es un problema global tenemos:

\section{Figura $\mathrm{N}^{\circ} 1$ \\ Costos del Covid-19}

La figura precisa en amplitud los efectos de la pandemia en la vida de los ciudadanos y en todos los sectores del país, en nuestra realidad de acuerdo a León (2020) que comenta la realidad española, que nada se distancia de nuestra realidad nos dice: "Se ha disminuido la actividad económica en forma temporal, lesionado el tejido productivo, y suspendido las actividades de numerosos sectores y lo que es peor con serias pérdidas en los ingresos de las familias, trabajadores independientes y el sector empresarial" $(p, 2)$.

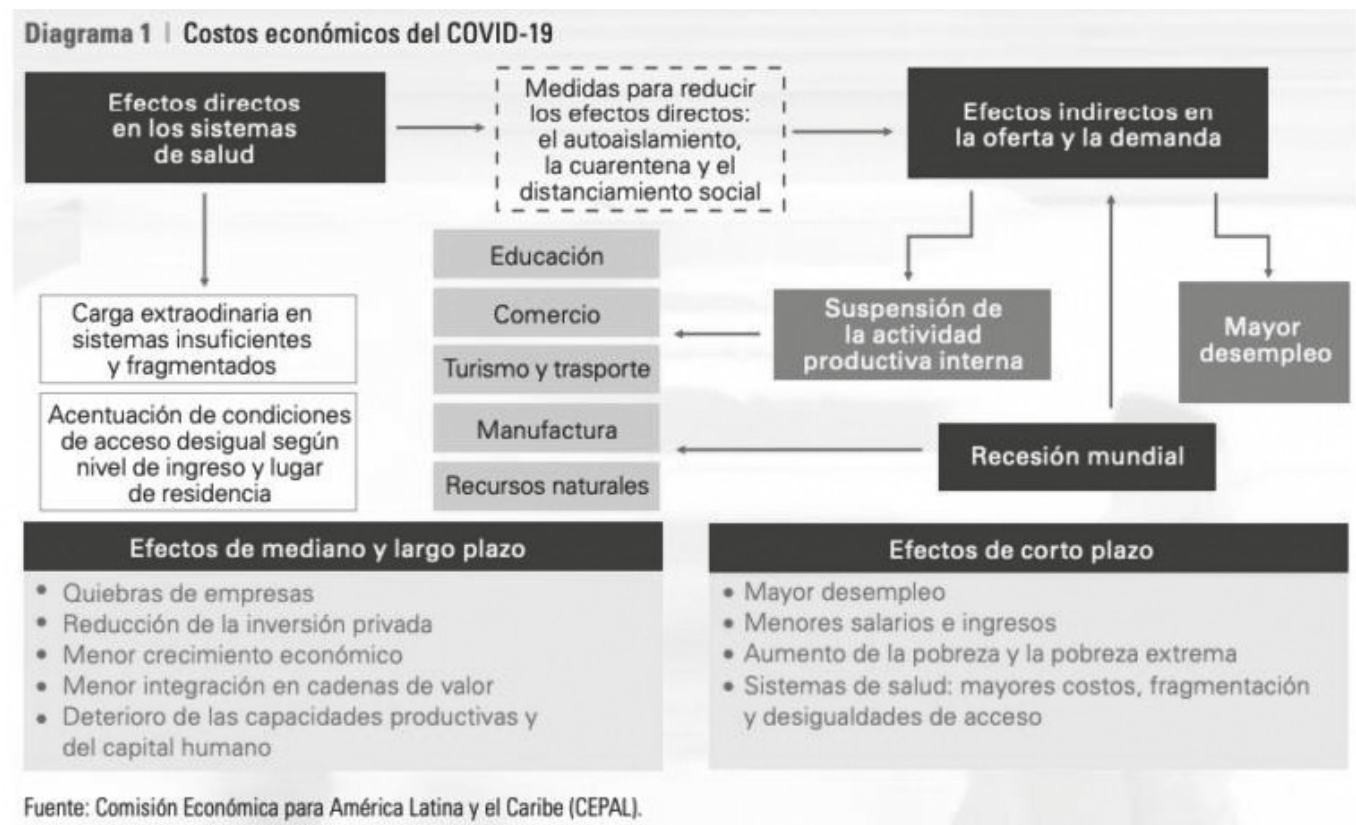

La misma situación atraviesan los diferentes países, algunos con mayores problemas como pudimos observar en el Ecuador, y nuestra realidad como bien sabemos se pone cada día peor ya al tercer mes de las medidas de aislamiento social.

Se menciona algunos de los efectos de dicha pandemia: "Caída del PBI, colapso y desborde del sistema sanitario en especial de la infraestructura hospitalaria, desempleo, hambre, aumento del 
nivel de pobreza, los sectores más golpeados son la construcción y el turismo"(Grados, 2020 p. 3). Estos efectos se están volviendo nefastos para nuestra economía, coincidiendo en perjuicios con las grandes recesiones, como la crisis de 1930, por la caída de los mercados norteamericanos y la crisis en 1983 como consecuencia del fenómeno del niño o la recesión entre 1988 y 1990, durante el gobierno de Alan García.

\section{Regulación del "estado de emergencia"}

El aislamiento ordenado por el estado inmovilizo a las personas y a los trabajadores haciendo imposible que puedan cumplir con sus obligaciones contractuales, esto es incumplimiento o retraso de los contratos pactados, por la situación de caso mayor, caso fortuito entre otras figuras jurídicas. Dichas figuras contractuales han cobrado una relevancia trascendental y no se ha visto su presencia en la dimensión actual, y que se ha dado como consecuencia de la pandemia.

Nuestra constitución regula un capitulo denominado "Régimen de Excepción" donde tanto el presidente en concordancia con el Consejo de Ministros tiene la facultad de decretar en un determinado plazo en todo el país o parte de él y comunicando al legislativo puede ordenar el estado de sitio y el estado de emergencia. Este último es el aplicado como estrategia para la lucha contra la pandemia, donde la característica más relevante es la restricción de "derechos fundamentales".

Los derechos fundamentales son producto de una larga lucha de los seres humanos desde épocas antiguas, derechos que se han posicionado e instrumentalizado en los instrumentos de protección de los derechos humanos tanto a nivel interno como supranacional. Los derechos humanos son producto de una larga lucha de los seres humanos desde épocas antiguas, derechos que se han posicionado e instrumentalizado en los instrumentos de protección de los derechos humanos tanto a nivel interno como supranacional.

Sobre la relevancia de los derechos humanos nos dice:

Los derechos humanos constituyen una preciada conquista de la vida social moderna. El instrumento supranacional de mayor trascendencia y el más grande pacto de unión universal que se haya propuesto la humanidad, se apoya fundamentalmente en el desarrollo y garantía del respeto de los derechos que tiene todo ciudadano, es la denominada "Carta de Naciones Unidas". (Parra, 2019 p, 14).

En nuestro país primero se declaró emergencia sanitaria y el índice de contagios nos obligó a declarar el estado de emergencia como precisa el Decreto Supremo 044-2020-PCM, del 15 de marzo del 2020, el cual dispuso un "aislamiento social obligatorio", que garantizaba todo lo relacionado al abastecimiento de los alimentos. Ahora esta institución es la que va ocasionar un nuevo panorama en el ámbito jurídico, sobre todo en el contractual. Así mismo se siguieron emitiendo decretos como el Decreto Supremo N 046-2020-PCM, que da mayores precisiones de las medidas tomadas y que es prorrogado por el Decreto Supremo Nº51-2020-PCM.

El Decreto Supremo 044-2020-PCM, del 15 de marzo del 2020, modifico sustancialmente la vida del país, porque diversos aspectos de la vida se han visto suspendidos en forma intempestiva para no decirlo menos. En el nivel económico, las nuevas medidas especialmente el aislamiento tiene una incidencia trascendental en la ejecución de los contratos. Los efectos no pueden ser reguladas por una sola figura jurídica, muy al contrario tendrá que optarse por diferentes instituciones como el caso de la imposibilidad sobreviniente, la imprevisión entre otros. (Ninamancco, 2020 p. 2) 
El derecho fundamental relevante en el estado de emergencia es la "suspensión del libre tránsito", y este accionar el que impacto en la esfera contractual, como el incumplimiento de los compromisos u obligaciones contractuales en sus diferentes modalidades, como el caso de un contrato de arrendamiento, contrato de préstamo o el objeto de nuestro tema del contrato de obra. En este último, es trascendental el componente de la presencia física, como el caso de los trabajadores para poder realizar el contrato de obra.

\section{Regulación del "caso fortuito" o "fuerza mayor"}

Se les ha señalado muchas veces como figuras jurídicas parecidas se diferencian, el caso fortuito, de acuerdo a la Casación № 1693-2014, Lima del 8 de marzo del 2016, es cuando el daño se puede evitar si se toman acciones de prevención, a través de una "diligencia normal", a diferencia de la "fuerza mayor" que a pesar de las acciones preventivas, era inverosímil que se produzca el daño. Como sería el caso de los desastres naturales.

En la realidad que estamos viviendo la enfermedad del Covid en sí misma es calificada jurídicamente como un supuesto de caso fortuito, y la medida de emergencia impuesta del aislamiento social obligatorio, ordenada por el estado, califica como un supuesto de fuerza mayor. Ambas situaciones están previstas en nuestra legislación contractual, es allí donde debemos buscar la solución a la problemática, obvio cuando no funcione un acuerdo o una negociabilidad como se han optado en algunos casos o se viene haciendo en otros países.

La figura jurídica de "fuerza mayor" denominado por los tradicionales "la mano de dios", por estar ante una situación imprevisible, que no se pudo evitar y tampoco se pudo prever, su importancia radica en el ámbito del derecho, porque determinando la configuración de dicha accionar, se podrá establecer la responsabilidad que corresponde por los daños.

En cuanto a las causales no imputables al deudor por las cuales también puede extinguirse la obligación, están: el caso fortuito y la fuerza mayor. El caso fortuito está referido generalmente a cualquier evento de la naturaleza que no permite el cumplimiento de la obligación; tal es el caso de los terremotos, aluviones, huaycos, naufragios, desastres, etc. La fuerza mayor supone fuerzas irresistibles pero debidas a actos del hombre, ajenos a la voluntad del deudor, como una guerra, una huelga, un cambio de régimen, de sistema de gobierno, etc. (Vigil. 2005 p. 170)

La Casación N 1764-2015, Lima del 15 de setiembre del 2018 señala al respecto:

Fuerza mayor es la procedencia no atribuible o imputable, que va consistir en un hecho irresistible, imprevisto o extraordinario, impidiendo que se ejecute la obligación contractual, así como determina que la obligación se cumpla en forma defectuosa, tardía o parcialmente. La figura en comentario se va oponer como un límite a la responsabilidad porque no hay cumplimiento de las obligaciones pactadas y no quedara librado si no presenta pruebas fehacientes de dicho caso fortuito y que en ellas no intervino el deudor.

De acuerdo a la posición de Pacheco (2005) respecto a los supuestos de los casos que estamos analizando ellos "deben resultar demostrados por quien los alegue, no debiendo el magistrado efectuar un prejuicio sobre dichos hechos por la simple razón de estar relacionados mayoritariamente a accidentes de la naturaleza" ( $p, 620)$; como en el caso de la pandemia. 
Un elemento medular cuando tratamos de esta figura jurídica es que la parte reclamante de un daño originado de la fuerza mayor, tiene que demostrar como factor trascendental no haber participado o contribuido a que ocurra un evento dañoso. La fuerza mayor genera dos efectos, que sea de tal nivel que impida la obligación o que exista por parte del obligado un cumplimiento no debido esto es parcial, defectuoso, tardío.

Tema relevante es determinar la existencia de las clausulas con la precisión de cosa fortuita o fuerza mayor, dichas clausulas deben estar expresamente pactadas por las partes que intervinieron en el contrato. Si existiere dicha cláusula se tendrá que respetar lo acordado en el contrato. Se tiene que seguir lo estipulado conforme a las reglas establecidos a través del consentimiento.

\section{El contrato de obra y la incidencia del Covid- 19}

Según Posada Torres (2015) citando a Messineo, destaca que "el contrato es la médula de la vida de los negocios y el instrumento práctico que realiza las más variadas objetivos de la vida económica, constituyendo un instrumento jurídico que viabiliza el tráfico patrimonial" (p.3). Por lo tanto el contrato tiene una finalidad económica, que va permitir la permuta de bienes y servicios, o mejor aún, permite el intercambio y transmisión de derechos y obligaciones.

En este contexto, estamos en un mundo moderno donde las instituciones jurídicas van transformándose y van adaptándose a los nuevos escenarios de tráfico comercial, ahora el ámbito contractual está reajustando sus precisiones ante esta nueva realidad la magnitud de una pandemia, ya se iniciaron, se van a iniciar una serie de proceso que nos darán nuevos criterios, a través de las casaciones, acuerdos plenarios o nuevas modificaciones a nuestro derecho sustantivo para tutelar los derechos de ambas partes en nuestro caso en los contratos de obra.

El Perú antes de la Pandemia a pesar de la crisis política y de todos sus problemas mantenía su crecimiento económico y se podía observar que se mantenía el boom inmobiliario, lo que significaba inversión y una serie de contratos de obra de construcción en todos sus niveles de magnitud, ello generaba trabajo, inversión y modernidad. Sobre la relevancia del contrato de obra señala

Como sabemos el sector construcción que dentro de su ámbito tiene infraestructura privada y pública, esta última con una legislación especial, pero que también utiliza los parámetros del derecho sustantivo civil, no ha detenido su crecimiento a pesar de la crisis económica, los eventos políticos y los desastres naturales. La actividad de la construcción, a diferencia de las otras actividades, es un fenómeno que se mantiene dinámico y que aporta un positivo porcentaje a nuestro $\mathrm{PBI}$, que genera mano de obra, esto es trabajo e ingresos que van a dinamizar la economía del país. Esta actividad tiene un soporte jurídico fundamental como es "el contrato de obra de construcción", dicha figura contractual, no se condice con la importancia de la relación jurídica de las partes que intervienen, esto es entre los comitentes y el contratista. (Román, 2017 p. 4)

En este caso surge la gran interrogante ante estos hechos imprevisibles quien va asumir los nuevos costos que ha ocasionado las disposiciones en torno a la pandemia, quien asume la responsabilidad la estructura de los costos.

En el momento de la presencia de la pandemia y de las disposiciones que se emitieron, la realidad del contrato de obra cambio significativamente, porque el contratista constructor para la realización de su trabajo necesita del personal que trabaja en la obra (ingenieros, maestros de obras, operarios, 
ayudantes etc.), y dichas personas necesitan desplazarse, y desde la emisión del Decreto Supremo 044-2020-PCM, con el impedimento de movilizarse, dichos trabajadores no se pueden desplazar en este caso al establecimiento del comitente.

De igual manera los suministros que tiene diferentes rubros se han paralizado, no solo en los insumos sino también respecto a las maquinarias que comúnmente se utilizan en los contrato de obra de construcción. Se paralizan las compras y se detiene todo el círculo activo en torno a la obra.

Entonces el periodo de aislamiento paralizó los diversos proyectos de infraestructura, relacionados a los contrato de obra regulados por nuestro derecho sustantivo civil.

Los primeros problemas que aparecen son los reclamos en torno a los gastos realizado y al tiempo perdido que en este caso son inevitables, ahora lo que es relevante desde la óptica de un contratista es el estudio exhaustivo de los remedios contractuales que se disponen y utilizar las acciones pertinentes para poder disminuir las pérdidas y proteger los intereses legítimos.

Como manifiesta Aceris Law (2020) "el efecto inmediato de la pandemia es la interrupción de la obra y el retraso de este de las actividades del proyecto que inevitablemente originara reclamaciones por tiempo y costos adicionales" ( $p, 2)$.

Un tema importante es una evaluación post periodo de aislamiento, por ello señala:

Para poder determinar concretamente el impacto económico de cada partida de la obra, porque del estudio de dicha realidad se pueden presentar los siguientes casos: Que el costo proyectado para la realización de la obra se incremente significativamente, porque el contratista- constructor ha venido haciendo el pago del remuneración de los trabajadores a pesar que no podían trabajar, así mismo hay un incremento de los costos de los materiales de construcción, se sigue pagando el arrendamiento de los diverso equipos que se utilizan en la construcción, con ello estaríamos ante un quiebre definitivo- en términos cuantitativos- del equilibrio económico entre la prestación del comitente y la contraprestación del contratista. (Santos, 2020 p.3)

Ante dichas situación compleja se plantean diversas figuras jurídicas que dependerán de la forma del contrato y de la voluntad de las partes. Se puede alegar excesiva onerosidad en la prestación (Artículo $1440^{\circ}$ de nuestro derecho sustantivo civil), otra situación seria la imposibilidad sobreviniente de la prestación, imposibilidad temporal de la prestación, sin culpa de las partes.

\section{Reglas de aplicación de los casos de fuerza mayor en el caso del Covid-19}

A diferencia de otros sistemas jurídicos, en el Paraguay, los efectos de estos eventos imprevisibles sobre las obligaciones y los contratos han sido bastante regulados, lo que permite establecer pautas generales para orientar a las personas sobre sus derechos y obligaciones ante eventos de tal magnitud.

A diferencia de otros sistemas jurídicos, nuestro derecho sustantivo, regula los efectos de dichas acciones o eventos imprevisibles respecto a las obligaciones y vínculos contractuales

Se legislan los efectos en caso de presentarse la figura de la fuerza mayor y las otras figuras que se presentan: 
1. Existiendo una relación contractual y hasta la fecha de la emisión del Decreto Supremo 044-2020-PCM (16 de marzo del presente), no se ha hecho la ejecución de ninguno de los compromisos del contrato, ambas parte pueden elegir la resolución del vínculo contractual basándose en que no se puede ejecutar, acorde a lo señalado en el artículo $1431^{\circ}$, que regula la figura jurídica de la imposibilidad cuando no tienen la culpa los contratantes, por ende el contrato se resuelve de pleno derecho.

Por lo tanto el deudor que está libre de la contraprestación tendrá que hacer la devolución de lo que hubiere recibido por el contrato de obra. Distinto sería el caso que las partes en el contrato hayan convenido que el riesgo este a cargo del acreedor.

Ahora si no ha existido un daño o detrimento importante en los contratos con prestaciones reciprocas, ambas partes pueden pactar que se suspenda y se amplié la ejecución del contrato. Se aplica lo señalado en el artículo $1316^{\circ}$ de nuestro derecho sustantivo civil. Esto es cuando la causa de la imposibilidad es de naturaleza temporal, el deudor no será responsable por el atraso mientras este perdure.

2. Existiendo la ejecución del contrasto en la fecha que se puso en vigencia el Decreto Supremo 044-2020-PCM (16 de marzo del presente), esto es las medidas de carácter urgente influyeron intempestivamente en la realidad del contrato, se puede elegir la disminución de la reducción de la prestación y la resolución del contrato, como lo precisa el artículo $1433^{\circ}$ de nuestro derecho sustantivo, que regula la imposibilidad de la prestación y el acreedor consiente que se cumpla parcialmente, se puede efectuar una disminución proporcional en la contraprestación. Como manifiesta el artículo el artículo $1151^{\circ}$ y $1153^{\circ}$, que regulan los casos de la aceptación de la prestación en forma parcial de la contraprestación y se exige la disminución de la contraprestación si no existiere culpa del deudor.

Todo ello no está exento que las partes puedan convenir la aplicación de la renegociación del contrato, suspender la obra o en todo caso acorde a los vaivenes de las normas de gobierno ampliar la ejecución de la obra, teniendo en cuento lo sustentado anteriormente.

Se regula también en el ámbito contractual la pérdida de contrato por caso fortuito o fuerza mayor., como precisa el artículo 1518 "El transferente va quedar liberado de responsabilidad si el bien que adolece de vicio se pierde por caso fortuito o fuerza mayor".

Tenemos el artículo 1962, que prescribe también con sentido liberatorio porque precisa que el autor no está obligado a la reparación cuando el daño producido fue a efectos de caso fortuito o fuerza mayor.

3. La imposibilidad de llegar a un acuerdo por las partes y porque cada uno buscara la defensa de su pretensión en este compleja realidad elegirá las vías del litigio a través de un proceso judicial, arbitral o conciliatoria. Nosotros obviamente nos inclinamos a la negociación, que es una de las características relevantes del contrato, con él se permite discutir que vía sea la más adecuada para las partes en este caso de fuerza mayor de una magnitud sin precedentes.

\section{Alteración del Equilibrio Económico Financiero de un contrato de obra.}

El contrato de obra es factible de situaciones de demora y de riesgo que pueden aparecer, como la situación excepcional que está atravesando el mundo entero, dicho accionar va afectar lo que Campos 
(2010) describe como el equilibrio económico-financiero del contrato, porque se afecta o distorsiona los elementos vitales de tal balance. Un contrato de obra tiene cuatro elementos trascendentales como son: precio, plazo, Secuencia Constructiva, Expediente Técnico, todos los elementos mencionados trabajan juntos, ni uno de ellos puede faltar. Si alguna faltara se presentará el desequilibrio y terminaría afectando a una de las partes, como lo que está pasando actualmente, para volver al estatus quo, tendríamos que modificar uno de los elementos para volver al equilibrio del contrato, situación que no sucede hasta el momento porque esta imprevisión continua, cuando termine se tendrá que hacer las modificaciones que corresponda a efectos volver a tener un contrato factible.

Como observamos la alteración de cualquiera de dichos elementos afecta el valor de la obra y además causa perjuicio, quien lo asume. Se presentan nuevos gastos para las partes del contrato, como los inconvenientes laborales y económicos con los trabajadores, maquinaria, insumos, servicios indirectos etc., el tema complejo es quien asume dicho perjuicio. Es claro que los riesgos dependen del tipo de contrato, si es un contrato de suma alzada, a precios unitarios etc., pero este supuesto del COVID-19 es un hecho realmente imprevisto, irresistible e impredecible, pero su concurrencia no basta, sino que además de todo ello no pueda ejecutarse la obra, por una continuidad del hecho fortuito que no permite volver a replantear por el momento dicho contrato. Las partes deben tener garantizado el derecho que les corresponde, sobre todo de conseguir el beneficio económico justo a través de la ejecución del contrato de obra.

\section{Conclusiones}

Los eventos imprevisibles a consecuencia de fenómenos como desastres naturales, guerras, epidemias, fueron regulados muy acertadamente por el derecho romano que previo las soluciones en el caso de que sucediera un evento de fuerza mayor o cosa fortuita, nuestro derecho sustantivo tiene regulada muy acertadamente todo este tipo de posibilidades, y tiene soluciones ante el impacto de la pandemia del Covid-19 en los contratos de obra en la realidad peruana.

Un contrato de obra para su realización cuenta con innumerables factores uno de ellos es la fuerzas laboral que da dinámica a la construcción paulatina de la obra, porque los trabajadores o especialistas en la construcción se tendrán que desplazar a la obra y esto se hizo imposible por la inmovilización social decretada por el presidente, así mismo el suministro de bienes también fue paralizado, todo ello ha generado una interrupción masiva de los contratos de obra con consecuencias jurídicas que son objeto de preocupación, análisis y consultas para poder darle solución.

Hoy en día se presenta ejecuciones tardías, defectuosas o parciales por parte de los que tiene que ejecutar la obra y así mismo se presentan problemas en la contraparte porque también se hace imposible realizar el pago o los casos de la excesiva onerosidad cometida por algún de las partes.

Las soluciones, negociabilidad, convenios que se viene dando o se van a dar en el futuro deben ser en base a la consenso de las partes, sino se tendrá que ajustar a las disposiciones del código civil que regula todas las aristas respecto a la fuerza mayor o cosa fortuita, se tendrá en cuenta la posición de las partes del cumplimiento de las obligaciones pactadas, de cumplir con las obligaciones que no han sido ejecutadas, y sobre todo como se ha incluido la cláusula de Fuerza mayor en el contrato. 


\section{REFERENCIAS BIBLIOGRÁFICAS}

- Aceris Law (2020) COVID-19 y disputas de construcción: Reclamaciones por tiempo y dinero, Recuperado el 27 de mayo del 2020 en

- Beltrán, J. (2005) Comentarios al Código Civil. Lima. Gaceta Jurídica.

- Campos. A. et al (2010) El contrato de obra pública: Lo que no dice la Ley de Contrataciones y Adquisiciones del Estado, pero debería decir. Lima. Círculo de Derecho Administrativo.

- Cepal (2020) Efectos económicos y sociales ante la pandemia 1/3. Informe recuperado el 26 de mayo del 2020 en https://www.panoramical.eu/america-latina-y-caribe/57070/

- Grados, P (2020) Los efectos del Covid-19 en la economía peruana. Lima. Universidad de Lima. Ninamancco, F. (2020) El Covid 19 y los contratos de arrendamiento. Lima. Revista La Ley, domingo 20 de marzo del 2020.

- Oliva, R. (2020) Cumplimiento de contratos durante el Covid-19. Algoritmo Legal. Madrid, recuperado el 25 de mayo del 2020 en https://www.algoritmolegal.com/e-business- empresadigital/cumplimiento-de-contratos-durante-la-pandemia-del-covid-19/

- Parra, S. (2019) Los conflictos sociales y los derechos fundamentales. Arequipa.2016-2018. Lima Universidad Federico Villareal.

- Posada, C. (2015) "Las cláusulas abusivas en los contratos de adhesión en el derecho colombiano", Revista de Derecho Privado, Universidad Externado de Colombia, N. ${ }^{\circ} 29$, JulioDiciembre.

- Podetti, H. (2004) Contrato de Construcción. Buenos Aires. Editorial Astrea.

- Román, A. (2017) El Contrato de Obra de Construcción en el sector privado peruano: Análisis del desequilibrio contractual existente en la negociación, suscripción y ejecución de los contratos de construcción. Lima. PUPC.

- Santos, P. (2020) Covid-19 en el Perú y sus implicancia en distintos contratos desde un enfoque de empresa. Lima. Recuperado el 25 de mayo en https://lpderecho.pe/covid-19implicancias-contratos-civiles-empresa/

- Vigil, C. (2005) Comentarios al Código Civil. Lima. Gaceta Jurídica

Fecha de recepción: 22 de mayo de 2020

Fecha de aceptación: 01 de junio de 2020 